\title{
Defending commercial surrogate motherhood against Van Niekerk and Van Zyl
}

\author{
Hugh V McLachlan Glasgow Caledonian University, Glasgow
}

\begin{abstract}
The arguments of Van Niekerk and Van Zyl that, on the grounds that it involves an inappropriate commodification and alienation of women's labour, commercial surrogate motherhood (CSM) is morally suspect are discussed and considered to be defective. In addition, doubt is cast on the notion that CSM should be illegal.
\end{abstract}

\section{Introduction}

Van Niekerk and Van Zyl give the answer "Yes" to their following two questions. "[Is there] anything intrinsically immoral about surrogacy arrangements from the perspective of the surrogate mother herself?" "Is there anything intrinsic to women's reproductive labour that should keep us from commodifying it or turning it into a form of 'alienated labour'?"2 I suspect that when they say "keep us", they are not talking merely about ethical considerations which might keep them from being involved with commercial surrogate motherhood but that they have in mind legislation also affecting the rest of us.

Van Niekerk and Van Zyl argue explicitly that commercial surrogate motherhood (CSM) is immoral. The impression might well be given that they present thereby implicitly a case for considering that it should be illegal. I shall suggest that their case for supposing that CSM is immoral is weak and, perhaps more importantly; that even if CSM is immoral, Van Niekerk and Van Zyl have not established that it should be illegal. The actual immorality of things is something other than the possible desirability of making them illegal.

\section{Immorality and illegality}

There is nothing intrinsically immoral about many activities which are rightly illegal. For instance, there is nothing intrinsically immoral about driving a motor car on the left side nor on the right side of a road although there are good reasons for passing

\section{Key words}

Commercial surrogate motherhood; ethics. laws concerning such behaviour. It becomes immoral to drive on one or other side of roads when but only when there is a legally supported convention concerning which side of the road should be preferred for normal forward motion.

In Scotland, although not in all other countries, it is illegal to be drunk in, to consume alcohol in, and to try to bring alcohol into stadia at which professional football matches are being played. Various and numerous people - and I am one of them - are very much in favour of the legislation. It is, they would say, by and large a very good idea to have such legislation in present-day Scotland. Footbạ matches here are far more pleasant and safer te attend than they used to be and football supporter when travelling to and from matches, cause less of nuisance to other people than they used to do. Yet, there is nothing intrinsically immoral about being drunk at a football match nor drinking at a football match nor taking drink into football matches. The legislation might be poor legislation if applied in Scotland to games other than football or if applied in places other than Scotland, with different habits, conventions, attitudes and so forth. Intrinsically, however, such behaviour is no more immoral in Scotland than elsewhere, nor more immoral at football matches than at other sporting activities.

It might be desirable to have a law against $\mathrm{X}$ even although it might not be immoral, in the absence of such a law, to do X. Even if CSM is not intrinsically immoral, there might be a good case for making it illegal.

Even if CSM is immoral, there might be a good case for refraining from making it illegal. It might be undesirable to have a law against $\mathrm{X}$ even if, even in the absence of such a law, $\mathrm{X}$ is immoral.

There are costs and consequences of passing, $\underset{\gtrless}{ }$ having and trying to enforce legislation. These costs $\varrho$ and consequences are sometimes not worth bearing. They are often unpredicted and unintended. It + would be a mistake to assume that the effect of 0 illegalising $\mathrm{X}$ will necessarily be to make occurrences of $\mathrm{X}$ less frequent. For instance, did prohibition make drinking and drunkenness less common in $\stackrel{\mathbb{Q}}{2}$ America? Perhaps not. What it did do, by creating a black market for the production and consumption of 
alcohol, was to make the production and consumption of alcohol very profitable and very attractive to criminals. Organised crime was given a huge boost, the results of which still reverberate in American society.

Often, more often I would say than not, actions which are immoral happen not to be illegal. Often too, actions which are immoral should not be illegal. Often, perhaps even usually, when we consider that a particular action is immoral, we do not thereby conclude that it should be illegal.

Tony Blair recently said, or so I am told, that he considers that it is immoral to vote for the Conservative Party. I am sure that he does not think that it should be illegal to vote for the Conservative Party.

I suspect that it is normally immoral (although not hugely so) to fail to use one's vote in a general election. Perhaps I am wrong but I do not think that such failure to vote should be illegal although it is illegal somewhere - in Australia I think.

It is immoral for politicians to make promises which they do not have the intention and might not have the ability to keep. Should it be illegal for them to do so? I do not know. I do not think so.

Suppose that I promise to meet a friend in town at 8 o'clock on a Tuesday evening. Suppose that as the arranged times approaches, I remember that Brookside is soon to come on the television and that the current story lines are particularly interesting. If I were to choose to fail to turn up in order that I could watch the programme then I would act immorally but I would not be doing anything that is, nor in my view should be, illegal.

\section{The Ten Commandments}

Consider the Ten Commandments. In, for instance, Britain, how many of the ten explicitly or implicitly proscribed actions are illegal? Not many of them. How many of them do you think are immoral? How many of them do you think should be illegal?

I think that, as a general thing, it is morally wrong, for instance, to bear false witness against your neighbour, to fail to honour your father and mother and to commit adultery. However, I am not thereby logically committed to the view that these actions should be illegal. I think that they should not be illegal. Certain sorts of false witnessing against one's neighbour, for instance, perjury and some libels and slanders should be illegal but not false witness as such. It is morally wrong, say, to say, when he did not, that your neighbour voted Labour but it should not be illegal to do so. One's attitude to one's parents is a matter which the state neither can nor should legislate about. In Scotland, adultery used to be a crime: it used, in fact, to be a capital offence. I do not think that adultery should be a criminal offence nowadays: I am certain that it should not be a capital offence.
Even if CSM is intrinsically immoral it does not follow that it should be illegal.

The consequences of making CSM illegal might well be undesirable. Suppose that CSM is made illegal. CSM might still occur. What will be the consequences of illegal CSM? They might be different from the consequences of CSM as such just as, for instance, the consequences of prohibition were different from the consequences of normal, legal alcohol production, sale and consumption.

Making, for instance, speeding, illegal similarly does not necessarily reduce instances of speeding but, dissimilarly, it does not produce a black market for speeding whatever other consequences it might have. Of course, the risks of creating a black market for CSM might be worth taking and, overall, it might be a good idea to make CSM illegal but all this would not follow necessarily from the fact, if it were a fact, that CSM is intrinsically immoral.

\section{Van Niekerk and Van Zyl on CSM}

\section{Van Niekerk and Van Zyl argue that:}

"The problem with surrogacy arrangements is therefore that it causes a woman to be pregnant while expecting her not to acknowledge the fact that she is expecting her child. It tries to divorce pregnancy from the conscious knowledge that you are going to give birth to your child. In this way the surrogate becomes a mere 'environment' or 'human incubator' for someone else's child". ${ }^{3}$

Their argument is based on the acceptance of the views on commercial surrogate motherhood of Elizabeth Anderson. They write:

“. . . Anderson's point is not that surrogacy is immoral because it is a form of alienated labour, but because pregnancy should not become an act of alienated labour. Being denied the legitimacy of one's perspective on one's labour, being alienated from your feelings and having to act against one's emotions is not wrong per se, but only wrong if the labour in question is women's reproductive labour (or another special form of labour). It is in this sense that surrogacy is similar to prostitution: not that both are forms of alienated labour, but that in both cases a physical capacity (sexual intercourse and gestation) that should be afforded special respect is degraded to a form of alienated labour. What lies at the heart of the objection that surrogacy is similar to prostitution, is that women's reproductive labour, like their sexuality, should not be compared to and treated in the same way as other forms of physical labour. Anderson says that '[p]regnancy is not simply a biological process but also a social practice. Many social expectations and considerations surround women's gestational labour, marking it off as an occasion for the parents 
to prepare themselves to welcome a new life into their family"". ${ }^{2}$

Once you become, say, married, you cannot always regard your own body and your own life in the same way you could when you were single. When you voluntarily become pregnant you cannot always regard your own body and your own life in the same way that you could before you were pregnant. If you become party to a contract pregnancy, then you cannot always regard your body and your pregnancy in the same way that you could if you did not involve yourself in such an arrangement. You might change your mind after you have agreed to part with the baby: your feelings about the CSM agreement might develop contrary to your own predictions concerning them. All this is true enough but it does not seem a reason for disfavouring such contractual and quasicontractual arrangements: it is, rather, a sort of description of them and, perhaps, a warning against entering into them too lightly.

I am not convinced that commercial surrogate motherhood "commodifies" people nor necessarily, say, undermines the moral autonomy proper to women nor the dignity and respect due to them. To treat reproductive labour as if it were a mere commodity would, no doubt, be to "degrade" it but it is far from clear that CSM need involve treating the reproductive labour, far less the "labourer", as a mere commodity.

\section{Different contexts}

People can have a cluster of attitudes towards the same thing or activity: they can value the same thing or activity differently in different contexts; they can value the same thing in similar contexts in different ways. If people pay a woman for her services in, say, carrying a fetus they are, in some respects, treating the service as a "commodified" one but it does not follow that they are necessarily treating it merely as that and it certainly does not follow that they need consider the surrogate mother or the carried child as being - any more than other mothers and other children - commodities. We might pay a taxi-driver to convey a heavy trunk, a mother and a child from one part of town to another: is this necessarily to treat a woman and/or a baby as if it were a trunk or a trunk as if it were a human being? Is it to treat the taxi driver as if she were a mere commodity or a mere aspect of a commodified service? It is possible - though I doubt whether it commonly happens that some people might have a problem in distinguishing between and appreciating the significance of the difference between the commodified service of surrogate motherhood and the non-commodifiable person who provides it but that, I would suggest, is a problem about and for those particular people: we do not require the state to intervene and pass laws against commercial surrogate motherhood merely because of this possibility and nor do we havem reason thereby for saying that commercial surrogate $\overrightarrow{\bar{\sigma}}$. motherhood is immoral.

Van Nierkerk and Van Zyl argue that there is $\overrightarrow{\vec{F}}$ something in particular about commercial surrogate? motherhood that renders it - unlike otherwise? similar contractual arrangements - immoral but $\frac{\bar{c}}{\bar{\rho}}$ their argument is weak. They say that the problem $\vec{\Phi}_{\bar{\phi}}$ with commercial surrogate motherhood is that $\varrho$ “. . . the surrogate becomes a mere 'environment' oro 'human incubator' for someone else's child". ${ }^{3}$

\section{Social meaning}

The surrogate mother "becomes" no such thing. In some respects she - or, rather, her body - is, or is like i an "environment" and a "human incubator" (as is, $\dot{\omega}$ in some respects, any potential mother's body). What is immoral about that? In other respects, given + that she is a human being, she is quite unlike an inanimate environment or incubator. She never is and never could become a mere "environment" nor a mere "human incubator".

Van Niekerk and Van Zyl stress that there is a "social meaning" to pregnancy. They say:

"As we have indicated above, the distinguishigge feature of human pregnancies is that they may alo entail a conscious knowledge of the significance $\bar{\omega}$ fo this physiological state and an active expectation of, and preparation for, the birth of a child. Although it is hardly 'natural' or 'normal' for a person to develop응 this kind of perspective on her (or his) pregnancy, we can all recognise that it is good. Yet contract preg- $\overrightarrow{\overrightarrow{0}}$ nancies are geared towards keeping the surrogate 3 from experiencing pregnancy and childbirth in this way. Instead, it asks the surrogate to relinquish her: ability to interpret and control the meaning or significance of her reproductive labour". ${ }^{4}$

Why need there be only one interpretation of one's pregnancy which is appropriate? Might there not be, $\frac{3}{3}$ in particular, feelings, interpretations and meanings appropriate to commercial surrogate motherhood? which are different from those appropriate to other pregnancies? Obviously, if someone agrees to become a commercial surrogate mother then she is not "free" to imagine that she has not become a com mercial surrogate mother nor "free" to interpret herN pregnancy as the pregnancy of a non-surrogate ${ }^{\omega}$ mother. Such is the nature of contracts. That is a reason why such arrangements should be undertakent? thoughtfully: it is not a reason for thinking that CSME is immoral nor for wanting to ban it. To make CSM illegal would be to prohibit mothers from makingo other particular interpretations of their pregnancy他 which they might (and sometimes do) want to make

Van Niekerk and Van Zyl write:

"Thus, instead of saying that reproductive labour is 
the most integral part of the female identity (as Pateman does), one can rather claim that the bond between a pregnant woman and her child is usually (or should be) an integral part of her pregnancy". ${ }^{3}$

In the case of commercial surrogate motherhood, perhaps such a bond is not and should not be integral to the pregnancy.

Van Niekerk and Van Zyl write:

"Because surrogacy arrangements by definition involve more than two people, all of whom can legitimately claim that $s / h e$ is the parent of the child, a conflict can in principle always arise about who should assume parental rights and responsibilities towards the child. It seems that this is a problem inherent to surrogacy arrangements, since one can never be certain that such a conflict will not arise. It is easy to praise a successful arrangement in retrospect, but the danger always exists that an arrangement one is planning would cause moral harm to the surrogate and/or the commissioning parents. . . . Unless one can ensure the legitimacy of the surrogate's bond with the child and her perspective on her pregnancy without thereby denying that of the commissioning couple, the surrogacy arrangement can always be said to be dehumanising or alienating". 5

One might say that it is easy to praise, for instance, a successful marriage in retrospect, but it is always possible that it could have produced misery for the husband and/or the wife and/or the children of the marriage. So what? Is marriage inherently problematical and alienating and intrinsically likely to lead to conflicts? Even if it is, so what? Would marriage thereby necessarily be immoral? Whether or not marriage is inherently problematical in any way and/or immoral, does it follow that it would be a good idea to make marriage illegal? Surely not!

\section{Conclusion}

I accept the Wittgenstein-inspired notion that those things which are "Xs" - for instance, games - must possess some or other of the defining features of Xs but that these features need not be common to all $\mathrm{Xs}$. There is a middle ground between nominalism and essentialism. ${ }^{6}$ I think that the theory is applicable to all general terms. It applies to terms like "knowledge" and "moral goodness" no less than to less interesting ones such as games. The features by virtue of which things are, say, known to be true or are morally good need not be the same in all instances of knowledge nor the same in all instances of moral goodness. Perhaps, for instance, utilitarianism accounts correctly for the moral wrongness of some actions and, say, Kantianism correctly accounts for the moral goodness of others. There might be other morally good actions where neither utilitarianism nor Kantianism can correctly account for the moral goodness concerned.

There is no sole criterion of, say, games, knowledge or moral goodness and, even it it turns out that there is, logically, there need not be. The same applies, I think, when " $X$ " stands for those particular actions which should be illegal: there are various factors which can count against the desirability of making particular actions illegal and various factors which can weigh in the other direction. For instance, it can count in favour of making some actions illegal that, even if they have negligible - if any - harmful social consequences, they are inherently not only wrong but very wrong because, say, of the reasons for which they were done and/or the spirit in which they were done. It can count in favour of making some actions illegal, whether or not they are morally wrong in themselves that they are very socially harmful. Sometimes, even when some particular actions are morally wrong and/or are socially harmful, it is wise not to make them illegal because of the overall consequences - and by "consequences" here, I have in mind not merely the amount of happiness and harm produced but the distribution of it - of the illegality, which are something other than the consequences of the actions in question.

For instance too, it can count against the advisability of making an action a crime that the resulting law cannot be or will not be enforced and that deviations from the resulting law cannot or will not be appropriately punished. Sometimes, the effects of the non-enforcement of particular legislation, including resultant disrespect for other potentially more readily enforceable legislation, is such that its non-existence would be preferable even when the law would be a very good law were it to be enforced. I suspect that much traffic legislation comes into this category. Perhaps the scarcely enforced and littleregarded British speed limits should be abolished: they could be replaced by recommendations and dangerous and reckless speeding could be prosecuted as dangerous or reckless driving. Yet, the complication arises that even when a law is a bad one in the sense that it would have been better not to have formulated it in the first place, its repeal, after it has been long established, can have bad consequences. Perhaps the repeal now of the speeding legislation would lead some people to drive more dangerously than they now do in the erroneous belief that vehicle speed was no longer of legal or ethical importance. Legislation is, indeed, a messy business.

When, precisely, in general, something is immoral and when, precisely, in general, something should be illegal, I make no pretence to know. Perhaps CSM is immoral. Perhaps, whether or not it is immoral, it should be illegal. I do not think that it is immoral and nor do I think that it should be illegal. That it should be legal and that it is not immoral is my firmly held view. Nothing which Van Niekerk and Van Zyl say in the article of theirs which I have discussed constitutes a reason for slackening my view. 
Van Niekerk and Van Zyl are undoubtedly correct in maintaining that commercial surrogate motherhood can, like many things in life (including normal motherhood), lead to problems and personal distress: people are taking a risk and might well be acting unwisely when they get involved, in any capacity, with surrogate motherhood. What they do not demonstrate is that surrogate motherhood is immoral nor that it should be illegal: that any of the parties involved are doing something which they ought not to do and/or should not be legally entitled to do. Van Niekerk and Van Zyl leave wide open both the independent questions of whether or not CSM is immoral and of whether or not it should be illegal.
Hugh V McLachlan, MA, PhD, is Lecturer in Sociolog in the Department of Social Sciences, Glasgor $\overrightarrow{\underline{*}}$. Caledonian University, Glasgow.

\section{References}

1 Van Niekerk A, Van Zyl L. The ethics of surrogacy women's reproductive labour. fournal of Medical Ethics 1995; 21: 345.

2 See reference 1: 346 .

3 See reference 1: 347 .

4 See reference 1: 348 .

5 See reference 1: 348-9.

6 McLachlan HV. Wittgenstein, family resemblances and $\vec{\omega}$ the theory of classification. International fournal of Sociology and Social Policy 1981; 1,1: 1-16. 